\title{
Genetic differentiation in bottlenose dolphins from South Australia: association with local oceanography and coastal geography
}

\author{
Kerstin Bilgmann ${ }^{1,2, *}$, Luciana M. Möller ${ }^{1,2}{ }^{\text {, }}$ Robert G. Harcourt ${ }^{1}$, Susan E. Gibbs ${ }^{1}$, \\ Luciano B. Beheregaray ${ }^{2}$
}

\begin{abstract}
${ }^{1}$ Marine Mammal Research Group, Graduate School of the Environment, and ${ }^{2}$ Molecular Ecology Laboratory, Department of Biological Sciences, Macquarie University, Sydney, New South Wales 2109, Australia
\end{abstract}

\begin{abstract}
For many marine organisms, including large, long-lived predators, the factors affecting connectivity between populations are still largely unknown. We assessed levels of genetic differentiation and dispersal patterns of bottlenose dolphins Tursiops sp. across Spencer Gulf and coastal areas west of the gulf in the Great Australian Bight, South Australia (SA), using data from mitochondrial DNA control region sequences and 6 microsatellite loci. Marked genetic differentiation and low migration were detected between dolphins of Spencer Gulf and those inhabiting coastal areas west of the gulf. We hypothesise that the restriction to dolphin gene flow is influenced by an oceanographic front at the mouth of Spencer Gulf that builds up over the austral summer and exhibits strong differences in water temperatures and salinity levels. It appears that the genetic subdivision reported here is a recent phenomenon, a finding consistent with the known geomorphologic history of the region. Coastal bottlenose dolphins from SA are evolutionarily divergent from other bottlenose dolphin species and are potentially under threat due to ongoing human-related mortality. The information from this study can, therefore, be used for the development of much-needed conservation management strategies.
\end{abstract}

KEY WORDS: Population genetic structure · Cetacean · Phylogeography · Marine connectivity • Microsatellites $\cdot$ Mitochondrial DNA $\cdot$ Temperature $\cdot$ Salinity

\section{INTRODUCTION}

Clarifying the genetic structure of populations and identifying patterns of dispersal and barriers to gene flow can significantly improve our understanding of a species' biology. Several studies have detected strong negative correlations between the degree of population genetic structure and the ability of a species to disperse (Bohonak 1999). For many marine organisms, the factors affecting connectivity between populations are still largely unknown. Interestingly, a growing number of recent studies have shown that marine populations are genetically more structured than predicted based on dispersal capabilities (reviewed in Palumbi 2004). Dispersal may be limited by oceanographic processes, such as ocean currents, salinity and temperature gradients, sea floor topology and other geographic features that may provide opportunities for isolation and differentiation (e.g. Jørgensen et al. 2005). Specific characteristics of coastal habitats, such as estuaries, can also drive adaptive divergence and genetic differentiation in marine organisms (e.g. Beheregaray \& Sunnucks 2001).

Several cetacean species show greater than expected population structure over relatively small geographic scales (Hoelzel et al. 2002). Cetaceans are social mammals and, like other mammals, they often show female-biased philopatric behaviour (e.g. Möller \& Beheregaray 2004). This can lead to significant population subdivision at maternally inherited genes, for 
example the mitochondrial DNA control region, even over small geographical scales (e.g. Hoelzel 1998). In some populations of bottlenose dolphins, males disperse more often and further than females (Tursiops spp., Krützen et al. 2004; T. aduncus, Möller \& Beheregaray 2004). However, other populations do not show significant differences in dispersal between the sexes (T. truncatus, Natoli et al. 2005). Differential dispersal by males and females has a major influence on the genetic structure of population. Therefore, it is important to select appropriate genetic markers with different modes of inheritance in order to successfully relate molecular genetics to population biology. Analysis of mitochondrial DNA (mtDNA) and nuclear markers, such as microsatellite DNA, allows the partitioning of maternal and biparental components of dispersal and population structure (Hoelzel et al. 2002). Combining genetic data from these 2 classes of markers with information on local coastal geography and oceanography may then contribute to an understanding of how these factors shape genetic structure in highly mobile cetacean species.

A number of cetacean species show segregation into marine habitats that exhibit different oceanographic features. Cetacean distribution is not uniform and is frequently associated with prey distribution (Hastie et al. 2004) and specific topographic features of an area (Cañadas et al. 2002). Restricted distribution may lead, over time, to genetic structuring of populations, and in some areas this structuring has been shown to be associated with ocean currents (Kasuya \& Ogi 1987), changes in salinity (Natoli et al. 2005) and the distribution of prey species (Fullard et al. 2000). An association between genetic structure and several oceanographic parameters including salinity and sea surface temperature has also been reported for bottlenose dolphins (Natoli et al. 2005).

Two species of bottlenose dolphins, Tursiops truncatus and T. aduncus, have been recognised worldwide (Rice 1998, Wang et al. 1999). T. truncatus has a broad distribution and is found both inshore and offshore in cool temperate to tropical waters around the world (Leatherwood et al. 1983), whereas T. aduncus is only present in coastal and estuarine waters of the Indian and western Pacific Oceans, including south-eastern Australia (Rice 1998, Wang et al. 1999, Möller \& Beheregaray 2001). The 2 species have been reported to occur in sympatry and parapatry (e.g. Wang et al. 1999, Hoelzel et al. 2002) and over a range of different habitats (e.g. Bearzi et al. 1997, Möller \& Beheregaray 2001). In South Australia (SA), the taxonomic status of coastal bottlenose dolphins Tursiops sp. has not yet been clarified (though see Kemper 2004). Recent genetic evidence, based on both mtDNA and microsatellite data, strongly suggests that coastal bottlenose dolphins from SA, Victoria and Tasmania are evolutionarily distinct from the 2 other recognised bottlenose dolphin species (Charlton et al. 2006, Möller et al. unpubl. data). The former is likely to represent an undescribed dolphin taxon more closely related to the common bottlenose dolphins $T$. truncatus than to the Indo-Pacific bottlenose dolphin T. aduncus (Charlton et al. 2006).

To date, no studies have been conducted on the genetic structure and dispersal of coastal bottlenose dolphins in SA. This information, however, is of great importance for the management of local dolphin populations due to ongoing mortality of dolphins through interactions with fisheries and finfish aquaculture, and intentional killings (Kemper \& Gibbs 2002, Kemper et al. 2005). This has been considered one of the most serious marine mammal bycatch problems in Australian waters (Shaughnessy et al. 2003). Since bottlenose dolphins in the area live in coastal habitats, they are also subject to other environmental pressures, such as coastal pollution (Evans 2003), and there is a concern that together these factors may negatively impact the viability of local dolphin populations (Shaughnessy et al. 2003, Kemper et al. 2005). A detailed knowledge of the genetic population structure and dispersal patterns of dolphins in this area will contribute to a better understanding of the species biology and the status of local dolphin populations.

In the present study we aim to clarify the population genetic structure and patterns of dispersal of bottlenose dolphins across Spencer Gulf and coastal areas west of the gulf in the Great Australian Bight, SA. This is relevant to marine scientists for several reasons. First, this study presents an opportunity to investigate the influence of oceanography and coastal geography in shaping population structure in a highly mobile marine organism. Second, coastal bottlenose dolphins from SA are evolutionarily divergent (they potentially represent an undescribed species), and their population genetic structure has never been assessed. Finally, information from this study can be used for the development of much-needed conservation management strategies for bottlenose dolphins in SA.

\section{MATERIALS AND METHODS}

Study area and samples. Biopsy sampling of freeranging bottlenose dolphins Trusiops sp. was conducted in 2 areas in SA: inside Spencer Gulf and in coastal areas west of Spencer Gulf, between 2004 and 2005. Within each area, biopsy samples were obtained from 3 and 2 sampling regions, respectively (Fig. 1). All 5 sampling regions are located between St. Francis Island in the west $\left(32^{\circ} 29^{\prime} \mathrm{S}, 133^{\circ} 17^{\prime} \mathrm{E}\right)$ and Yorke 


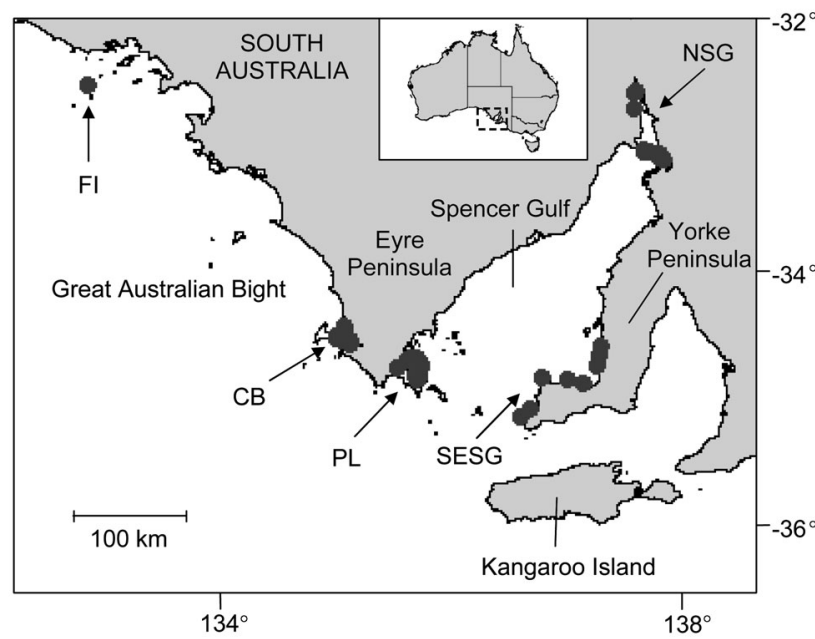

Fig. 1. Tursiops sp. Map showing sampling regions in South Australia. Dots represent sampling localities within each region (FI: St. Francis Island; CB: Coffin Bay; PL: Port Lincoln; NSG: north Spencer Gulf; SESG: southeast Spencer Gulf). Upwelling areas are located west of Kangaroo Island and west of the tip of Eyre Peninsula. The oceanographic front occurs at the mouth of Spencer Gulf

Peninsula in the east $\left(35^{\circ} 18^{\prime} \mathrm{S}, 136^{\circ} 50^{\prime} \mathrm{E}\right)$ and include both gulf and open coastal water environments (Fig. 1). Spencer Gulf is a large and shallow inverse estuary that lacks freshwater inflow and is characterised by elevated water temperatures and a net fluid loss causing high levels of salinity (Pritchard 1967). The exchange of water masses between Spencer Gulf and outside areas is limited, and during the majority of months each year the water in the gulf exhibits much higher sea surface temperatures and salinity levels, and, as a consequence of this, an oceanographic front forms at the mouth of the gulf (Petrusevics 1993).

Bottlenose dolphins were biopsy sampled using either a hand-held biopsy pole for bow-riding dolphins (Bilgmann et al. 2007), or a rifle modified to deliver biopsy darts (Krützen et al. 2002). Biopsies at each sampling site were obtained from individuals from multiple dolphin groups, including solitary individuals. No samples were collected from dependent calves. All biopsy samples were preserved in $100 \%$ ethanol.

Genetic methods. Extraction of DNA and genetic sexing: Total DNA was extracted from approximately $100 \mathrm{mg}$ of subcutaneous tissue using a salting out protocol. The sex of each individual was determined by amplifying via the polymerase chain reaction (PCR) fragments of the ZFX and SRY genes (Gilson et al. 1998) using PCR conditions reported in Möller et al. (2001).

Mitochondrial DNA (mtDNA) screening and sequencing: A mtDNA control region fragment of approximately 450 bp was amplified by PCR using the primers Dlp-1.5 (5'-TCA CCC AAA GCT GRA RTT CTA-3') and Dlp-5 (5'-CCA TCG WGA TGT CTT ATT TAA GRG GAA-3') (Baker et al. 1993). PCR conditions consisted of an initial denaturation step at $93^{\circ} \mathrm{C}$ for 3 min, followed by a touch-down PCR with 9 cycles, decreasing the annealing temperature by $1^{\circ} \mathrm{C}$ per cycle. Denaturation was at $93^{\circ} \mathrm{C}(30 \mathrm{~s})$, annealing at 63 to $55^{\circ} \mathrm{C}(1 \mathrm{~min})$ and extension at $72^{\circ} \mathrm{C}(1 \mathrm{~min})$. A cycle of $93^{\circ} \mathrm{C}(30 \mathrm{~s}), 53^{\circ} \mathrm{C}(30 \mathrm{~s})$ and $72^{\circ} \mathrm{C}(1 \mathrm{~min})$ was then repeated 27 times, followed by a final extension of $72^{\circ} \mathrm{C}$ for $5 \mathrm{~min}$ (see Möller \& Beheregraray 2001). The $10 \mu \mathrm{l}$ radiolabelled reaction mix for each sample contained 50 to $100 \mathrm{ng}$ template DNA, $12 \mathrm{pmol}$ of each primer, $0.5 \mathrm{U}$ of Taq DNA polymerase (PROMEGA or QUIAGEN), $200 \mu \mathrm{M}$ of dATP, dCTP, dGTP and dTT, $2 \mathrm{mM} \mathrm{MgCl}_{2}, 50 \mathrm{mM} \mathrm{KCl}, 10 \mathrm{mM}$ Tris- $\mathrm{HCl}(\mathrm{pH} 9.0$ at $25^{\circ} \mathrm{C}$ ) and $0.05 \mu \mathrm{l}\left[\alpha_{-}{ }^{33} \mathrm{P}\right] \mathrm{dATP} 1000 \mathrm{Ci} \mathrm{mmol}^{-1}$. When using PROMEGA Taq polymerase, the reaction mix also contained $0.1 \%$ Triton X-100, and when using QUIAGEN Taq polymerase it contained $25 \mathrm{mM}$ $\left(\mathrm{NH}_{4}\right)_{2} \mathrm{SO}_{4}$.

Amplified mtDNA control region fragments were screened for sequence variation by the single-stranded conformation polymorphism (SSCP) analysis as described in Sunnucks et al. (2000). A minimum of 2 ind. of each SSCP phenotype was selected to prepare fresh PCR products, which were electrophoresed on $2 \%$ agarose gels. Each product band was then excised from the gel and purified with an UltraClean 15 DNA purification kit (MO BIO) and sequenced in an ABI 377 automated DNA sequencer according to the manufacturer's instructions.

In order to confirm that 'offshore' bottlenose dolphins Tursiops truncatus were not sampled and incorrectly included in the analysis, we compared the mtDNA sequences of SA dolphins with a large mtDNA data set of 'offshore' and 'inshore' south-eastern Australian bottlenose dolphins (e.g. Möller \& Beheregaray 2001, L. M. Möller unpubl. data) and with other T. truncatus sequences available from the GenBank database.

Microsatellite genotyping: Samples were PCR genotyped at 7 polymorphic cetacean microsatellite loci: KW2, KW12 (Hoelzel et al. 1998), EV1, EV37 (Valsecchi \& Amos 1996), MK5, MK6 and MK8 (Krützen et al. 2001). PCR cycling conditions were as reported in Möller et al. (2001). Loci were amplified in $10 \mu \mathrm{l}$ radiolabelled reactions, each contained 50 to $100 \mathrm{ng}$ of template DNA, $12 \mathrm{pmol}$ of each primer, $0.5 \mathrm{U}$ of Taq DNA polymerase (PROMEGA), $20 \mu \mathrm{M}$ of dATP, $200 \mu \mathrm{M}$ of dCTP, dGTP and dTTP, $2 \mathrm{mM} \mathrm{MgCl}_{2}$, $50 \mathrm{mM} \mathrm{KCl}, 10 \mathrm{mM}$ Tris- $\mathrm{HCl}\left(\mathrm{pH} 9.0\right.$ at $\left.25^{\circ} \mathrm{C}\right), 0.1 \%$ Triton X-100 and 0.05 to $0.07 \mu \mathrm{l}\left[\alpha_{-}{ }^{33} \mathrm{P}\right] \mathrm{dATP} 1000 \mathrm{Ci}$ $\mathrm{mmol}^{-1}$.

Unsuccessful PCR reactions were repeated either once or twice. For each locus, selected individuals 
were re-amplified and re-genotyped to test the reliability of the PCR. Samples that showed identical microsatellite genotypes and the same mtDNA control region haplotype and that were of the same sex were considered samples of the same individual (biopsy sampled twice) and were included only once in the data set. Samples with identical microsatellite genotypes were identified with MS TOOLS Ver. 3.1 (Park 2001). The microsatellite data set was then screened for genotyping errors with the software MICROCHECKER Ver. 2.2.3 (Van Oosterhout et al. 2004). When MICRO-CHECKER suggested the presence of null alleles for a locus, its null allele frequency was estimated with CERVUS Ver. 2.0 (Marshall et al. 1998).

Mitochondrial DNA data analysis: Mitochondrial DNA control region sequences were cleaned and aligned with the program SEQUENCHER 3.0 (Gene Code Corporation). We used ARLEQUIN Ver. 2.000 (Schneider et al. 2000) to estimate genetic variability at the haplotype $(h)$ and nucleotide $(\pi)$ levels, and to calculate pairwise genetic differentiation and their statistical significance. Pairwise differentiation between samples was estimated by $F_{\mathrm{ST}}$, which takes only haplotype frequency into account, and $\Phi_{\mathrm{ST}}$, which also incorporates a genetic distance. The program MODELTEST Ver. 3.06 (Posada \& Crandall 1998) was employed to determine the genetic distance that showed the best-fit model of sequence evolution for the data set, using the Akaike Information Criterion (AIC). Finally, we examined genealogical relationships among mtDNA haplotypes using a haplotype network constructed with the statistical parsimony method implemented in TCS Ver. 1.21 (Clement et al. 2000).

Microsatellite data analysis: Exact test for deviations from Hardy-Weinberg equilibrium (HWE) and tests for linkage disequilibrium were carried out in GENEPOP Ver. 3.4 (Raymond \& Rousset 1995) based on a Markov chain method and 1000 iterations. Evaluation for deviations from HWE were performed applying the sequential Bonferroni procedure (Rice 1989). To identify first-order relatives among the sampled individuals, we undertook a relatedness analysis in KINSHIP 1.3 (Goodnight \& Queller 1999). This is important in order to avoid a bias when assessing levels of genetic differentiation, because a high number of first-order relatives in a particular region can lead to overestimates of population structure.

GENEPOP was also used to estimate the mean number of alleles per locus $(A)$, allele frequencies and expected $\left(H_{\mathrm{E}}\right)$ and observed $\left(H_{\mathrm{O}}\right)$ heterozygosities. Allelic richness (AR), a measure of the mean number of alleles per locus that takes the differences in sample size into account, was calculated using FSTAT Ver. 2.9.3 (Goudet 2001). Levels of genetic divergence at microsatellite loci and their significance were calcu- lated between all pairs of sampling sites by computing $F_{\mathrm{ST}}$ in ARLEQUIN. Sex-specific $F_{\mathrm{ST}}$ values and their significance were calculated in addition. We also used ARLEQUIN to perform a hierarchical analysis of molecular variance (AMOVA), pooling samples into different geographic groups and testing these groupings for significance in amounts of molecular variance. The AMOVA was carried out using the locus-by-locus approach with 10000 permutations.

For the analysis of fine-scale genetic structure, we undertook an assignment test in GENECLASS Ver. 2.0 (Piry et al. 2004) that uses multilocus genotypic data to assign individuals to their population of origin. In the assignment test, the likelihood of an individual's multilocus genotype belonging to a candidate set of populations is computed, and the individual is assigned to the population where the likelihood of its genotype is highest. Individuals with a likelihood of $<5 \%$ to a particular population were not assigned to that population. The 'leave one out' procedure was applied in order to reduce the bias of assigning the current individual to its source population. We chose a Bayesian method for the assignment test because it has shown to perform better in computer simulations (Cornuet et al. 1999). A simulation of 10000 randomly generated genotypes was then applied. Sampling error associated with estimating allele frequencies and differences in genetic diversity between populations were taken into account.

In addition, we employed the Bayesian clustering method implemented in the program STRUCTURE Ver. 2.0 (Pritchard et al. 2000) to test for the presence of population structure and to estimate the most likely number of populations $(K)$ in the data set. The length of the initial burn-in period was set at $10^{5}$ iterations, followed by a run of $10^{6}$ Markov chain Monte Carlo (MCMC) repetitions, for values of $K$ between 1 and 5 . We used the admixture and correlated allele frequency models and provided no prior information on sampling location when running the analysis. Consistency of the estimates of $P(X / K)$ for the allele frequency model was assessed by carrying out 5 independent runs with $K$ ranging from 1 to 5 , using the same values for burn-in and MCMC repetitions.

Recent migration rates (over the last few generations) between dolphins from Spencer Gulf and coastal areas west of the gulf were estimated using the Bayesian multilocus genotyping approach implemented in the program BAYESASS Ver. 1.3 (Wilson \& Rannala 2003). This method accounts for unequal migration rates, and populations are not required to be in either migration-drift or Hardy-Weinberg equilibrium. For estimating posterior probability distributions of parameters, the MCMC was run for a total of $6.0 \times$ $10^{6}$ iterations, with the first $10^{6}$ iterations acting as 
burn-in to allow the chain to reach stationarity. Samples were collected every 2000 iterations to infer posterior probability distributions.

The relationship between genetic distance at microsatellites $\left(F_{\mathrm{ST}}\right)$ and geographical distances was analysed using the Mantel procedure implemented in GENEPOP. Distances were measured in kilometres following the contours of the coastline and in a straight line across the Spencer Gulf. The significance of

Table 1. Tursiops sp. Sampling regions in South Australia with abbreviations, number of samples and genetically identified sex of sampled individuals

\begin{tabular}{|lcrrc|}
\hline $\begin{array}{l}\text { Region and } \\
\text { abbreviation }\end{array}$ & $\begin{array}{c}\text { Sample Female } \\
\text { size }\end{array}$ & Male & $\begin{array}{c}\text { Unknown } \\
\text { sex }\end{array}$ \\
\hline St. Francis Island (FI) & 13 & 6 & 7 & 0 \\
Coffin Bay (CB) & 21 & 9 & 11 & 1 \\
Port Lincoln (PL) & 22 & 16 & 6 & 0 \\
North Spencer Gulf (NSG) & 16 & 5 & 11 & 0 \\
Southeast Spencer Gulf & 12 & 7 & 5 & 0 \\
(SESG) & & & & \\
\hline
\end{tabular}

Table 2. Tursiops sp. Variable positions of 10 mtDNA control region haplotypes. Dots represent nucleotide identity in the sequence of haplotype 1 (H1)

\begin{tabular}{|c|c|c|c|c|c|c|c|c|c|}
\hline & & 1 & 2 & 2 & 2 & 2 & 3 & 3 & 4 \\
\hline & 4 & 6 & 0 & 0 & 3 & 6 & 0 & 3 & 1 \\
\hline & 1 & 6 & 6 & 9 & 7 & 4 & 8 & 1 & 4 \\
\hline H1 & $\mathrm{T}$ & $\mathrm{T}$ & $\mathrm{T}$ & $\mathrm{G}$ & A & $\mathrm{G}$ & $\mathrm{G}$ & $\mathrm{T}$ & $\mathrm{T}$ \\
\hline H2 & . & $\mathrm{C}$ & . & . & . & . & . & . & . \\
\hline H3 & . & . & . & A & . & A & . & C & . \\
\hline $\mathrm{H} 4$ & . & . & . & . & . & . & A & . & . \\
\hline H5 & . & . & $\mathrm{C}$ & . & . & . & A & . & . \\
\hline H6 & . & . & . & . & . & A & . & C & . \\
\hline H7 & . & . & . & . & . & . & A & C & C \\
\hline H8 & $\mathrm{C}$ & . & . & . & . & . & . & . & . \\
\hline H9 & . & . & . & . & . & . & . & . & C \\
\hline H10 & . & . & . & . & $\mathrm{G}$ & . & . & . & . \\
\hline
\end{tabular}

results was tested by iterating 10000 times. To test for sex bias in dispersal, 3 different methods were employed using the FSTAT software, which compares: (1) sex-specific $F_{\mathrm{ST}}$, (2) sex-specific mean corrected assignment indices (AIc) and (3) mean relatedness between same-sex pairs. A randomised approach with 10000 permutations was employed to test whether the difference in dispersal between the sexes was significant.

\section{RESULTS}

\section{Samples}

A total of 92 bottlenose dolphin samples were collected from 5 regions in SA, 3 within Spencer Gulf and 2 in coastal areas west of the gulf (Table 1, Fig. 1). We identified 8 dolphins, which were sampled twice, showing identical microsatellite genotypes at all loci, the same mtDNA haplotype and matching sex. These individuals were only included once in the data set. The analysis of mtDNA control region sequences showed, as expected from field work observations (i.e. dolphin morphology, school size and coastal distribution), that we did not sample any 'offshore' bottlenose dolphins Tursiops truncatus (comparisons not shown). All sampled individuals were identified as belonging to the southern Australian coastal bottlenose dolphin Tursiops sp. (Charlton et al. 2006, Möller et al. unpubl. data).

\section{Genetic variability}

A sequence fragment of $446 \mathrm{bp}$ of the mtDNA control region was aligned for all 84 samples. A total of 10 unique haplotypes characterised by 9 variable positions were found (Table 2) (GenBank Accession Numbers EF192140 to EF192149). All substitutions were transitions. Haplotypic diversity $(h)$ differed little be-

Table 3. Tursiops sp. Summary of genetic variability based on mtDNA control region sequences and 6 microsatellite loci (NH: number of haplotypes; NA: mean number of alleles per locus; $h$ : haplotypic diversity; $\pi$ : nucleotide diversity; AR: allelic richness; $H_{\mathrm{E}}$ : mean expected heterozygosity; $H_{\mathrm{O}}$ : mean observed heterozygosity). Values in parentheses are standard errors. For region abbreviations see Table 1

\begin{tabular}{|c|c|c|c|c|c|c|c|c|}
\hline \multirow[t]{2}{*}{ Region } & \multirow[t]{2}{*}{ Sample size } & \multicolumn{3}{|c|}{ Mitochondrial DNA } & \multicolumn{4}{|c|}{ Microsatellites } \\
\hline & & $\mathrm{NH}$ & $h$ & $\pi$ & NA & $\mathrm{AR}$ & $H_{\mathrm{E}}$ & $H_{\mathrm{O}}$ \\
\hline FI & 13 & 4 & $0.77(0.06)$ & $0.0035(0.0025)$ & 6.3 & 6.2 & $0.72(0.06)$ & $0.72(0.10)$ \\
\hline $\mathrm{CB}$ & 21 & 3 & $0.55(0.07)$ & $0.0047(0.0030)$ & 6.3 & 5.8 & $0.65(0.08)$ & $0.63(0.09)$ \\
\hline PL & 22 & 4 & $0.70(0.05)$ & $0.0048(0.0031)$ & 5.8 & 5.2 & $0.67(0.05)$ & $0.67(0.06)$ \\
\hline NSG & 16 & 5 & $0.77(0.08)$ & $0.0046(0.0030)$ & 5.3 & 4.4 & $0.66(0.04)$ & $0.66(0.07)$ \\
\hline SESG & 12 & 5 & $0.80(0.08)$ & $0.0034(0.0024)$ & 6.2 & 6.5 & $0.65(0.08)$ & $0.65(0.08)$ \\
\hline
\end{tabular}


Table 4. Tursiops sp. Genetic variation at 7 microsatellite loci for each sampling region, and for the 2 populations (n: number of individuals; AR: allelic richness; $H_{\mathrm{O}}$ : observed heterozygosity; $H_{\mathrm{E}}$ : expected heterozygosity). ${ }^{*}$ Loci that showed significant deviation $(p<0.05)$ from Hardy-Weinberg equilibrium prior to Bonferroni corrections. For region abbreviations see Table 1

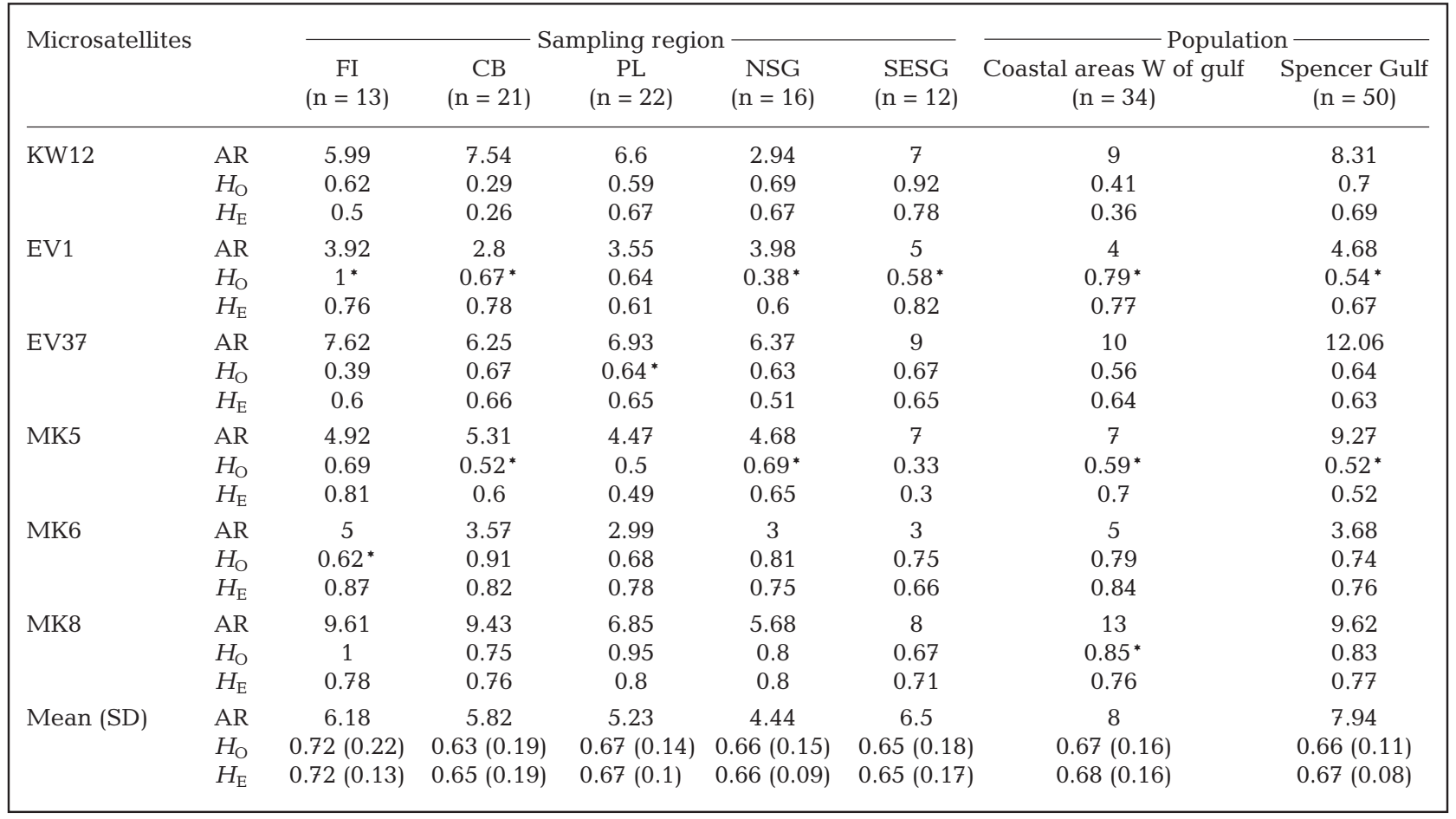

tween sampling regions, except for the $\mathrm{CB}$ region (Table 3). Samples from this region showed lower diversity, despite its comparatively larger sample size (Table 3 ). Levels of nucleotide diversity $(\pi)$ were relatively low and similar for all 5 regions (Table 3).

For microsatellites, we detected high null allele frequency $(28 \%)$ in the locus KW2. As a result, data from that locus were excluded from the analysis. The total number of alleles observed across the remaining 6 loci ranged between 5 and 15, with AR differing only slightly in 4 of the 5 regions, showing lowest values in the NSG region (Tables 3 \& 4). Expected and observed

Table 5. Tursiops sp. Pairwise fixation indices between 5 sampling regions in South Australia based on mtDNA control region sequences and 6 microsatellite loci. Mitochondrial $\Phi_{\mathrm{ST}}$ values are above the diagonal; microsatellite $F_{\mathrm{ST}}$ values are below $\left({ }^{*} p<0.05 ;{ }^{*} p<0.01\right)$. See Table 1 for abbreviations

\begin{tabular}{|lccccl|}
\hline & FI & CB & PL & NSG & SESG \\
\hline FI & & $0.165^{*}$ & 0.042 & $0.220^{* *}$ & $0.128^{*}$ \\
CB & 0.014 & & -0.007 & $0.367^{* *}$ & $0.328^{* *}$ \\
PL & $0.071^{* *}$ & $0.063^{* *}$ & & $0.285^{* *}$ & $0.194^{*}$ \\
NSG & $0.064^{* *}$ & $0.084^{* *}$ & 0.014 & & $0.218^{* *}$ \\
SESG & $0.081^{* *}$ & $0.098^{* *}$ & $0.027^{*}$ & $0.035^{*}$ & \\
\hline
\end{tabular}

heterozygosities were similar among sampling regions (Tables 3 \& 4). After sequential Bonferroni corrections no significant departures from Hardy-Weinberg equilibrium were observed across populations or loci.

\section{Genetic differentiation}

For the mtDNA data set, the $\Phi_{\text {ST }}$ pairwise comparisons were performed using the Tamura \& Nei (1993) model of sequence evolution, assuming equal base frequencies as suggested by MODELTEST. Significant population differentiation was detected for most pairwise comparisons between sampling regions for both $F_{\mathrm{ST}}$ and $\Phi_{\mathrm{ST}}$. Nonsignificant differentiation was only found between 2 sampling region comparisons: PL versus FI and PL versus CB. Since $F_{\mathrm{ST}}$ and $\Phi_{\mathrm{ST}}$ showed similar patterns, we only report values for $\Phi_{\mathrm{ST}}$ (Table 5). For microsatellites, we also found significant genetic differentiation for most sampling region comparisons using $F_{\text {ST }}$. Nonsignificant differentiation was only detected between FI and CB and between PL and NSG (Table 5).

Interestingly, all comparisons based on microsatellites between sampling regions from Spencer Gulf and regions west of the gulf resulted in highly significant 


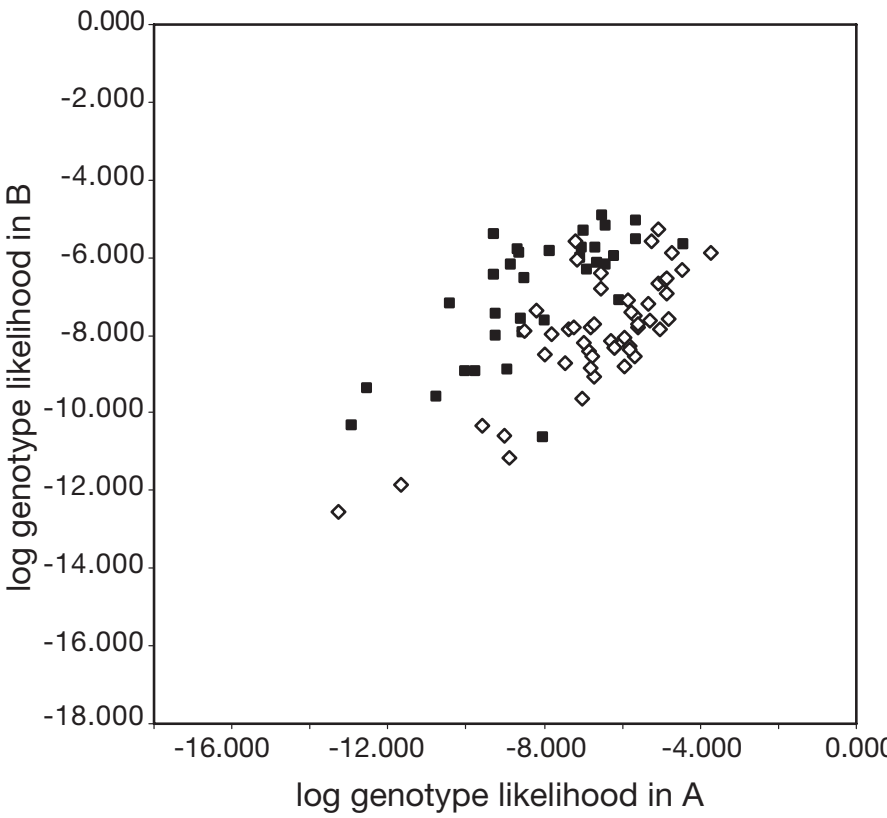

Fig. 2. Tursiops sp. Assignment plot of genotype likelihood values from 5 sampling regions to Populations A (Spencer Gulf) and B (west of the gulf). ( $\diamond)$ Spencer Gulf individuals; (匹) individuals from west of gulf

values for $F_{\mathrm{ST}}$ (Table 5). These were all greater than the pairwise comparisons between regions within the gulf and between regions in coastal areas west of the gulf, indicating a marked genetic differentiation between dolphins from Spencer Gulf and west of the gulf. Sex-specific $F_{\mathrm{ST}}$ comparisons between pooled individuals from Spencer Gulf and pooled individuals from coastal areas west of the gulf revealed that gene flow between the 2 geographic regions is restricted for both males $\left(F_{\mathrm{ST}}=0.056, \mathrm{p}<0.01\right)$ and females $\left(F_{\mathrm{ST}}=0.074\right.$, $\mathrm{p}<0.01)$. The AMOVA, including both males and females, confirmed that a significant proportion of molecular variance $\left(F_{\mathrm{ST}}=0.057, \mathrm{p}<0.01\right)$ could be explained by differences between dolphins from these 2 geographic regions. Testing for an association between genetic and geographic distances among all sampling regions based on microsatellites failed to reveal a significant correlation $(p=0.073)$. This indicated that a simple model of isolation by distance does not provide a good explanation for the genetic differentiation detected. The relatedness analysis revealed that the proportion of closely related individuals ( 0.5 to $1.2 \%$ ) in the data set was negligible and similar across regions. Therefore, a bias in the detection of genetic differentiation due to first-order relatives was not given in our data set.

The assignments of individuals (based on multilocus microsatellite data) to the area where they were born agreed with the general results based on $F_{\mathrm{ST}}$. Most individuals sampled in Spencer Gulf or in coastal areas west of the gulf were genetically assigned to their area of origin (Fig. 2). Only a few individuals $(n=8)$ were assigned to the opposite area and considered potential migrants ( $p<0.5$ ) (Fig. 2).

The analysis with the program STRUCTURE also showed that individuals from Spencer Gulf and coastal areas west of the gulf are genetically differentiated. Most dolphins from west of the gulf had a high membership probability to the population west of the gulf, from which they originated, and a large proportion of dolphins from Spencer Gulf had a high membership probability to the Spencer Gulf population (Fig. 3). Although this analysis visually assigned individuals into 2 different populations for every run when setting $K=2$ (Fig. 3), assessing the ln probabilities of the data revealed that the posterior probability for each value of $K$ was highest at $K=1$. The estimated mean ln probability of $K$ over 5 runs for $K=1$ was -1580.1 ; for $K=2$, -1636.2 ; for $K=3,-1832.0$; for $K=4,-1854.8$; and for $K=5,-1975.7$, with the posterior probability for $K=1$ approximating 1 . For a minority of the runs, large variances among the posterior probabilities were observed,

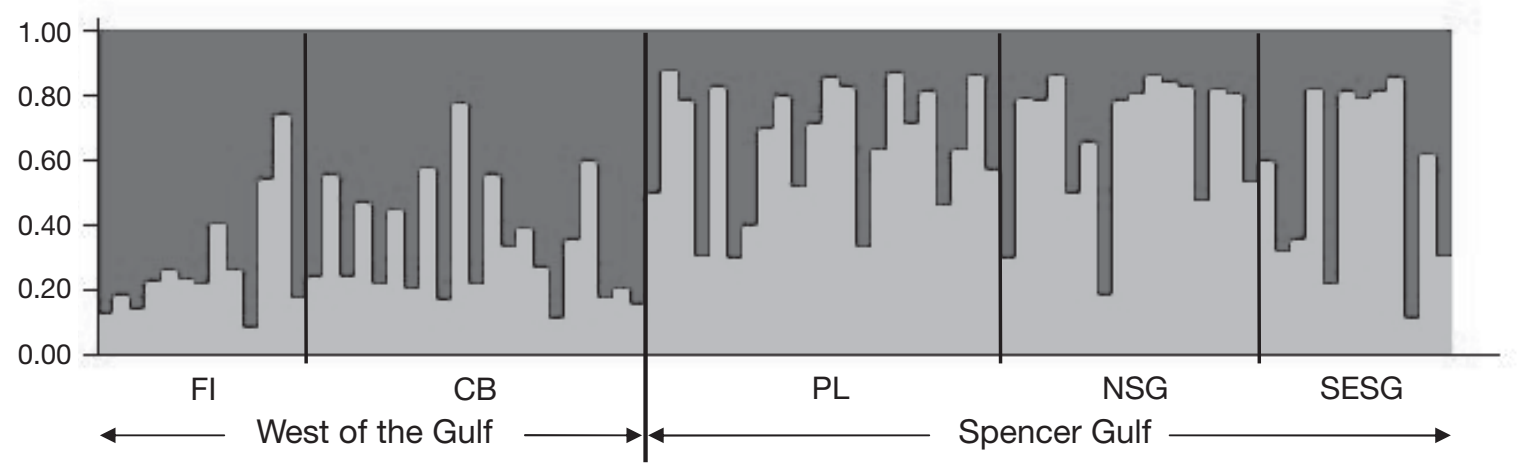

Fig. 3. Tursiops sp. STRUCTURE results for 5 sampling regions in South Australia (see Table 1 for abbreviations). Each vertical column represents 1 individual dolphin, and the separation of the column into 2 shades of grey represents the estimated probability of belonging to one or the other population 


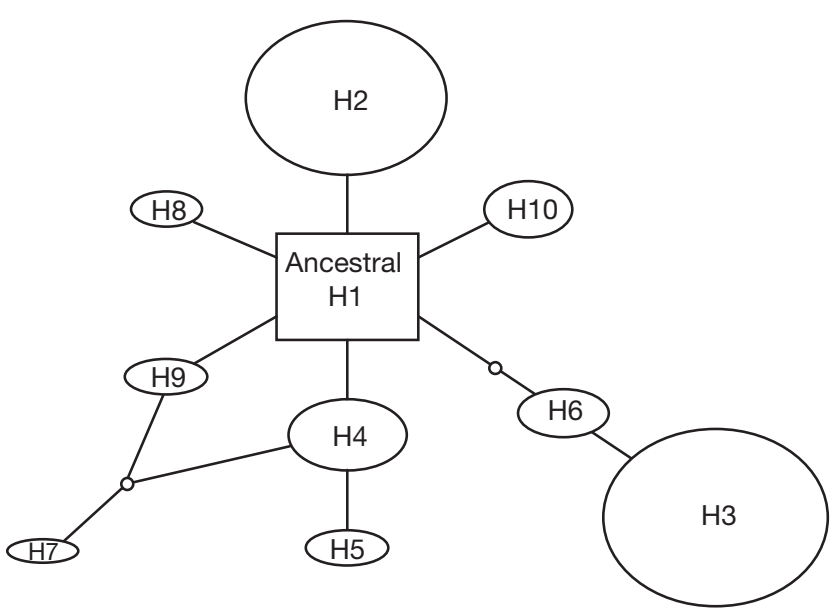

Fig. 4. Tursiops sp. Haplotype network for mtDNA control region sequences. The size of the ovals is proportional to the number of individuals showing the particular haplotype. Haplotype H1 was considered to be the ancestor lineage based on coalescence theory. Each line indicates 1 mutation between haplotypes; small circles between connecting lines represent missing haplotypes

indicating that the MCMC chain had not converged. This generally occurs in data sets where signals of genetic differentiation are relatively weak (Waples \& Gagiotti 2006), and is probably due to low to moderate gene flow between the 2 areas. Nonetheless, the results from STRUCTURE visually suggest that there is genetic differentiation between the gulf dolphins and the dolphins from the west of the gulf. In agreement with this, the mean proportion of membership $(q)$ for Spencer Gulf dolphins in the gulf population was $q=0.66$, whereas this value for dolphins from coastal areas west of the gulf in the coastal population was $q=0.63$. The relatively weak signal of population differentiation detected probably relates to the performance of STRUCTURE being highly dependent on sample size and number of loci (Evanno et al. 2005).

We also assessed recent migration rates of dolphins between Spencer Gulf and coastal areas west of the gulf by describing the mean of the posterior probabilities for these rates. Results of BAYESASS suggest that rates of migration between the 2 areas are very low. The estimated migration rate $(m)$ from Spencer Gulf to coastal areas west of the gulf was slightly higher $(m=0.1 ; 95 \% \mathrm{CI}$ : 0.019 and 0.229 ) than the migration rate in the opposite direction $(m=$
0.022; $95 \%$ CI: 0.001 and 0.069). The $95 \%$ CI of these estimates suggest that the data contain sufficient information for reliably estimating migration rates.

\section{Genealogical relationships}

The reconstructed haplotype network (Fig. 4) suggests a recent scenario of matrilineal diversification, consistent with the low values of nucleotide diversity obtained. It appears that most mtDNA haplotypes have recently originated from $\mathrm{H} 1$. This haplotype showed the highest outgroup probability, and is located in the centre of the network-typical of an ancestral lineage. Distribution and frequency of haplotypes between sampling regions inside Spencer Gulf and between those from coastal areas west of the gulf differ substantially (Fig. 5).

\section{Sex-biased dispersal}

For dolphins from Spencer Gulf, $F_{\mathrm{ST}}$ values and mean relatedness were significantly higher for females than males (Table 6). The mean AIc was also higher for females than males in this area, although this difference was not significant (Table 6). Altogether, the results suggest higher female philopatry and malebiased dispersal for gulf dolphins. For dolphins west of the gulf, $F_{\mathrm{ST}}$ values, mean AIc and mean relatedness were not significantly different between males and females (Table 6).

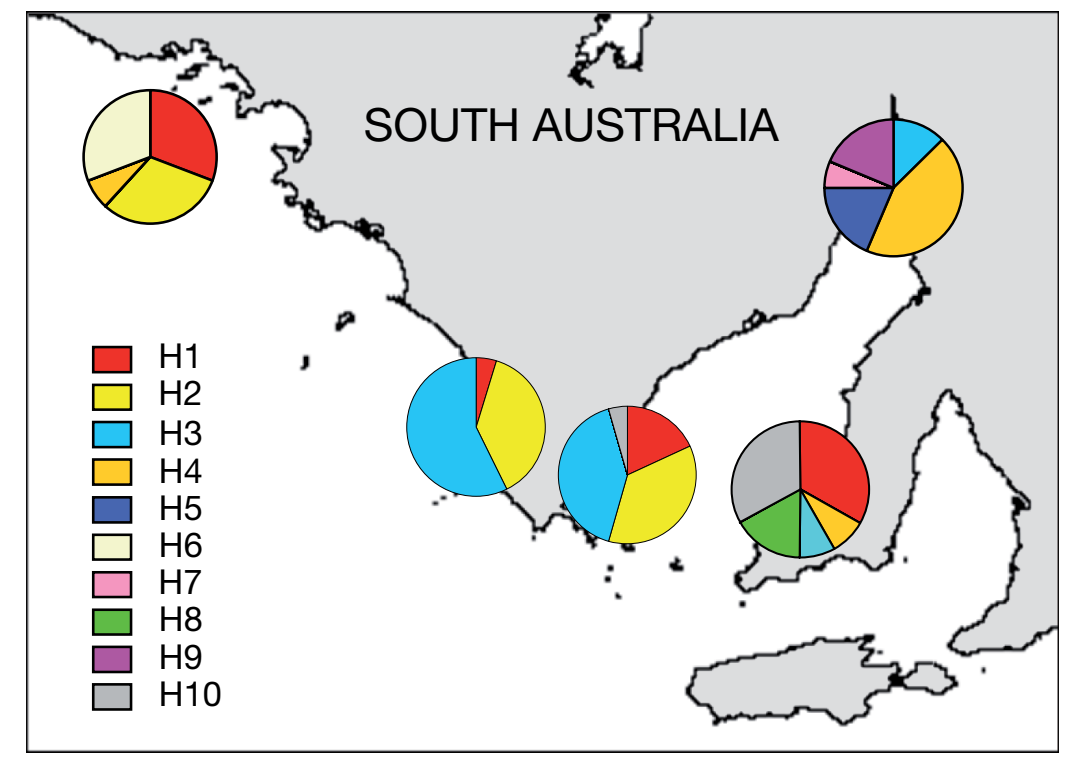

Fig. 5. Tursiops sp. Geographical distribution and frequency of mtDNA haplotypes in 5 sampling regions in South Australia 
Table 6. Tursiops sp. Sex-specific $F_{\mathrm{ST}}$, mean relatedness between same-sex pairs and the mean corrected assignment index (AIc)

\begin{tabular}{|lrrr|}
\hline & Females & Males & p-value \\
\hline West of Spencer Gulf & & & \\
$F_{\text {ST }}$ & 0.0212 & 0.0164 & 0.4413 \\
Relatedness of same-sex pairs & 0.0417 & 0.0323 & 0.4418 \\
Mean AIc & 0.1424 & -0.1266 & 0.3976 \\
Spencer Gulf & & & \\
$F_{\text {ST }}$ & 0.0588 & -0.0017 & 0.0200 \\
Relatedness of same-sex pairs & 0.1093 & -0.0035 & 0.0270 \\
Mean AIc & 0.0967 & -0.1177 & 0.3710 \\
\hline
\end{tabular}

\section{DISCUSSION}

\section{Association between genetic differentiation and oceanographic features}

We identified a genetic pattern consistent with marked population structure and restricted migration in coastal bottlenose dolphins Tursiops sp. from SA. The pattern can be best explained by the separation of dolphins into 2 geographic populations: Spencer Gulf and coastal areas west of Spencer Gulf. This division was supported by a number of analyses based on both nuclear DNA (microsatellites) and mtDNA. In addition, we found no correlation between geographic and genetic distance. The marked genetic differentiation between gulf and coastal samples over the relatively small geographic distance is noteworthy. Interestingly, the restriction of gene flow around the mouth of Spencer Gulf appears to coincide with an oceanographic front that is characteristic for the area.

This front arises due to a restricted exchange of water masses between Spencer Gulf and outside areas. Spencer Gulf is an inverse estuary that lacks freshwater inflow and exhibits elevated water temperatures and salinity levels (Pritchard 1967, Petrusevics 1993). At the entrance to Spencer Gulf, upwellings occur west of Kangaroo Island and west of the tip of Eyre Peninsula during spring and summer (Fig. 1). During these upwellings cold, nutrient-rich water is brought to the surface with the sea surface temperature differential reaching its highest values (between 3 and $3.5^{\circ} \mathrm{C}$ ) during summer. This differential coexists with, and overlays, strong benthic temperature and salinity differentials of 7 to $8^{\circ} \mathrm{C}$ and 1.2 to $1.5 \mathrm{ppt}$, respectively (Petrusevics 1993).

In other regions of the world gradients in temperature and salinity seem to be important variables shaping the genetic structure of marine taxa (e.g. Nielsen et al. 2003, Jørgensen et al. 2005). For example, areas that differ in surface temperature and salinity coincide well with zones of low gene flow among herring popu- lations in the Baltic Sea (Jørgensen et al. 2005). Similarly, populations of cod and turbot that show low genetic differentiation within the North Sea and within the Baltic Sea display marked genetic differentiation in the transition zone between the 2 areas - a zone that is characterised by a sharp salinity gradient (Nielsen et al. 2003).

Associations between the distribution of cetacean populations and sea surface temperatures, salinity changes and local currents have also been described (e.g. Kasuya et al. 1988, Fullard et al. 2000, Natoli et al. 2005). Isolation between 2 populations of long-finned pilot whales in the North Atlantic occurred between areas that differed in sea surface temperatures (Fullard et al. 2000). Temperature was also a primary factor determining differentiation of 2 populations of closely related forms of short-finned pilot whales off the Pacific coast of Japan - these 2 forms exhibit genetic, morphometric and life-history differences (Kasuya et al. 1988). Natoli et al. (2005) found that, along a transect from the Black Sea to Scotland, bottlenose dolphin Tursiops truncatus populations exhibited boundaries that coincided with regions distinguished by several oceanographic parameters, including sea surface temperature, salinity levels, primary productivity and topography. These boundaries also reflected intraspecific genetic differentiation in a number of different marine species (see Natoli et al. 2005). The correlation we observed in SA adds to this list and corroborates the suggestion that temperature gradients in SA play a role in the establishment and maintenance of coastal biogeographical patterns (O'Hara \& Poore 2000).

Oceanographic features themselves are not likely to affect the distribution of the dolphins directly, but rather indirectly by influencing the distribution and abundance of prey species that exhibit thermal and saline sensitivity (e.g. Kasuya et al. 1988, Fullard et al. 2000, Jørgensen et al. 2005). Prey abundance and distribution are thought to be the most important factors in determining the occurrence and movements of cetaceans (Hastie et al. 2004). For example, in the western North Atlantic and Gulf of Mexico, the distribution of coastal bottlenose dolphins is closely associated with local prey distribution, whereby physical barriers to prey dispersal are likely to have an indirect effect on gene flow among dolphin populations (Dowling \& Brown 1993).

In $\mathrm{SA}$, the distribution of sardines Sardinops sagax, an important species in the diet of coastal bottlenose dolphins in the area (Kemper \& Gibbs 2002), exhibits a gap in distribution between the mouth of Spencer Gulf and eastern areas of the Great Australian Bight (Ward et al. 2006). This gap, which is probably associated with cold sea surface temperatures caused by upwellings (Ward et al. 2006), potentially represents an 
important factor influencing the pattern of genetic structure detected in bottlenose dolphins.

\section{Contrasting dispersal patterns in SA bottlenose dolphins}

Our analysis of sex-biased dispersal showed contrasting patterns for the 2 coastal bottlenose dolphin populations. While dolphins from Spencer Gulf showed male-biased dispersal, there was no obvious sex bias in dispersal in the population west of the gulf. Significant differentiation for mtDNA between sampling regions in Spencer Gulf also indicated high levels of female philopatry for gulf dolphins. However, gene flow between dolphins from Spencer Gulf and western coastal areas was restricted for both sexes.

Möller \& Beheregaray (2004) described a similar pattern to that observed in Spencer Gulf, i.e. higher female philopatry and male-mediated gene flow for bottlenose dolphins Tursiops aduncus inhabiting 2 embayments in south-eastern Australia. This pattern may arise from female bottlenose dolphins benefiting more than males from the familiarity with local habitats and food resources (Möller \& Beheregaray 2004). Differential use of habitat in bottlenose dolphins is suggested to be possibly a consequence of resource specialisation (e.g. Hoelzel 1998, Natoli et al. 2005, Möller et al. in press). Habitat type differs markedly between Spencer Gulf and coastal areas west of the gulf (IMCRA Technical Group 1998). Since prey distribution is largely dependent on habitat type, it is possible that resource specialisation by gulf females accounts for the contrasting patterns in dispersal observed in the 2 SA bottlenose dolphin populations.

\section{Population history}

The shallow, star-like genealogy observed for the mtDNA data set (Fig. 4) indicates that, from a historical perspective, all coastal bottlenose dolphins in the study area have a single and recent population origin. Significant differences in frequency of mtDNA haplotypes were detected between most sampling regions, but no lineage sorting was observed. It appears that relatively little time has passed for lineage sorting at the mtDNA control region between the 2 populations. During the last glacial maximum (LGM), around $17000 \mathrm{yr}$ ago, the SA continental shelf (including the area of Spencer Gulf) was exposed above sea level (Belperio et al. 1983). Sea level rises set lower areas of Spencer Gulf under water around $10000 \mathrm{yr}$ ago, reaching its present configuration around 6600 yr ago (Belperio et al. 1983). We propose that the restriction to gene flow detected between bottlenose dolphins from Spencer Gulf and the area west of the gulf occurred after the LGM, when habitats inside Spencer Gulf became available.

\section{Conclusions and management implications}

Altogether, the data suggest that bottlenose dolphins from Spencer Gulf are genetically differentiated from those in coastal areas west of the gulf, in the Great Australian Bight. There is a clear concordance between the observed restriction to gene flow at the mouth of Spencer Gulf and a strong drop in sea surface temperatures and salinity levels characteristic for this area. The data not only agree well with local oceanographic features, but also with coastal geography and with differences in prey distribution. Our results are concordant with the idea that genetic differentiation between the 2 populations is recent and likely took place after the LGM, when dolphins colonised Spencer Gulf.

Our findings have important conservation management implications for bottlenose dolphins in SA, especially in light of the considerable human-related mortality of dolphins in the region due to interactions with fisheries, finfish aquaculture and intentional killings (Kemper \& Gibbs 2002, Kemper et al. 2005). Considering the level of genetic differentiation between individuals from Spencer Gulf and coastal areas west of the gulf, the low migration rates of dolphins between the 2 areas and the concordance of population boundaries with specific oceanographic features, we suggest that populations from these 2 areas should be considered as separate entities for management purposes.

Acknowledgements. We thank the Department of Environment and Heritage (DEH) in SA for providing a research permit (A24720), and the DEH and the South Australian Research and Development Institute (SARDI) for logistical support during field work. We are grateful to C. Kemper, curator of mammals at the South Australian Museum, for her contribution to the development of this research project. We are thankful to R. Wilson and 4 anonymous reviewers for their comments on an earlier draft of the manuscript. The project was funded by Macquarie University, the Graduate School of Environment, the Linnean Society of NSW and by SARDI. We also are grateful to S. Murray-Jones, S. Clarke, P. Rogers, and L. McLeay and several volunteers for their fieldwork support. Animal ethics approval was provided by DEH (42/2003) and by the Animal Ethics Committee at Macquarie University (2003/23-2). K.B. was supported by an international Macquarie University Research Scholarship (iMURS).

\section{LITERATURE CITED}

Baker CS, Perry A, Banister JL, Weinrich MT and 10 others (1993) Abundant mitochondrial DNA variation and worldwide population structure in humpback whales. Proc Natl Acad Sci USA 90:8239-8243 
Bearzi G, Notarbartolo-Di-Sciara G, Politi E (1997) Social ecology of bottlenose dolphins in the Kvarneric (northern Adriatic Sea). Mar Mamm Sci 13:650-668

Beheregaray LB, Sunnucks P (2001) Fine-scale genetic structure, estuarine colonization and incipient speciation in the marine silverside fish Odontesthes argentinensis. Mol Ecol 10:2849-2866

Belperio AP, Hails JR, Gostin VA (1983) A review of holocene sea levels in South Australia, Vol 3, Monograph series. Department of Geography, James Cook University of North Queensland, Townsville, p 37-47

Bilgmann K, Griffiths OJ, Allen SJ, Möller LM (2007) A biopsy pole system for bow-riding dolphins: sampling success, behavioral responses and test for sampling bias. Mar Mamm Sci 23:218-225

Bohonak AJ (1999) Dispersal, gene flow, and population structure. Q Rev Biol 74:21-45

Cañadas A, Sagarminaga R, Garcia-Tiscar S (2002) Cetacean distribution related with depth and slope in the Mediterranean waters off southern Spain. Deep-Sea Res Part I 49: 2053-2073

Charlton K, Taylor AC, McKechnie SW (2006) A note on divergent mtDNA lineages of 'bottlenose' dolphins from coastal waters of southern Australia. J Cetacean Res Manag 8:173-179

Clement M, Posada D, Crandall KA (2000) TCS: a computer program to estimate gene genealogies. Mol Ecol 9: 1657-1659

Cornuet JM, Piry S, Luikart G, Estoup A, Solignac M (1999) New methods employing multilocus genotypes to select or exclude populations as origins of individuals. Genetics 153:1989-2000

Dowling TE, Brown WM (1993) Population structure of the bottlenose dolphin (Tursiops truncatus) as determined by restriction endonuclease analysis of mitochondrial DNA. Mar Mamm Sci 9:138-155

Evanno G, Regnaut S, Goudet J (2005) Detecting the number of clusters of individuals using the software STRUCTURE: a simulation study. Mol Ecol 14:2611-2620

Evans K (2003) Pollution and marine mammals in the southern hemisphere: Potential or present threat? In: Nick G, Hindell M, Kirkwood R (eds) Marine mammals: fisheries, tourism and management issues. CSIRO, Collingwood, p 400-446

Fullard KJ, Early G, Heide-Jorgensen MP, Bloch D, RosingAsvid A, Amos W (2000) Population structure of longfinned pilot whales in the North Atlantic: a correlation with sea surface temperature? Mol Ecol 9:949-958

Gilson A, Sylvanen M, Levine KF, Banks JD (1998) Deer gender determination by polymerase chain reaction: validation study and application to tissues, bloodstains, and hair forensic samples from California. Calif Fish Game 84: 159-169

Goodnight KF, Queller DC (1999) Computer Software for performing likelihood tests of pedigree relationship using genetic markers. Mol Ecol 8:1231-1234

Goudet J (2001) FSTAT, a program to estimate and test gene diversities and fixation indices, Ver 2.9.3. Available at www2.unil.ch/popgen/softwares/fstat.htm

Hastie GD, Wilson B, Wilson LJ, Parsons KM, Thompson PM (2004) Functional mechanisms underlying cetacean distribution patterns: hotspots for bottlenose dolphins are linked to foraging. Mar Biol 144:397-403

Hoelzel AR (1998) Genetic structure of cetacean populations in sympatry, parapatry, and mixed assemblages: implications for conservation policy. J Hered 89:451-458

Hoelzel AR, Potter CW, Best PB (1998) Genetic differentiation between parapatric 'nearshore' and 'offshore' populations of the bottlenose dolphin. Proc R Soc Lond B 265: $1177-1183$

Hoelzel AR, Goldsworthy SD, Fleischer RC (2002) Population genetic structure. In: Hoelzel AR (ed) Marine mammal biology: an evolutionary approach. Blackwell Science, Oxford, p 325-352

IMCRA Technical Group (1998) Interim marine and coastal regionalisation for Australia: an ecosystem-based classification for marine and coastal environments, Ver 3.3. Environment Australia, Department of Environment, Sport and Territories, Canberra

Jørgensen HBH, Hansen MM, Bekkevold D, Ruzzante DE, Loeschcke V (2005) Marine landscapes and population genetic structure of herring (Clupea harengus L.) in the Baltic Sea. Mol Ecol 14:3219-3234

Kasuya T, Ogi H (1987) Distribution of mother-calf Dall's porpoise pairs as an indication of calving grounds and stock identity. Sci Rep Whales Res Inst 38:125-140

Kasuya T, Miyashita T, Kasamatsu F (1988) Segregation of two forms of short-finned pilot whales off the Pacific coast of Japan. Sci Rep Whales Res Inst 39:77-90

Kemper CM (2004) Osteological variation and taxonomic affinities of bottlenose dolphins, Tursiops spp., from South Australia. Aust J Zool 52:29-48

Kemper CM, Gibbs SE (2002) Dolphin interactions with tuna feedlots at Port Lincoln, South Australia and recommendations for minimising entanglements. J Cetacean Res Manag 3:283-292

Kemper CM, Flaherty A, Gibbs SE, Hill M, Long M, Byard RW (2005) Cetacean captures, strandings and mortalities in South Australia 1881-2000, with special reference to human interactions. Aust Mamm 27:37-47

Krützen M, Valsecchi E, Connor RC, Sherwin WB (2001) Characterization of microsatellite loci in Tursiops aduncus. Mol Ecol Notes 1:170-172

Krützen M, Barre LM, Möller LM, Heithaus MR, Simms C, Sherwin WB (2002) A biopsy system for small cetaceans: darting success and wound healing in Tursiops spp. Mar Mamm Sci 18:863-878

Krützen M, Sherwin WB, Berggren P, Gales N (2004) Population structure in an inshore cetacean revealed by microsatellite and mtDNA analysis: bottlenose dolphins (Tursiops sp.) in Shark Bay, Western Australia. Mar Mamm Sci 20:28-47

Leatherwood S, Reeves RR, Foster L (1983) The Sierra Club handbook of whales and dolphins. Sierra Club Books, San Francisco, CA

Marshall TC, Slate J, Kruuk LEB, Pemberton JM (1998) Statistical confidence for likelihood-based paternity inference in natural populations. Mol Ecol 7:639-655

Möller LM, Beheregaray LB (2001) Coastal bottlenose dolphins from southeastern Australia are Tursiops aduncus according to sequences of the mitochondrial DNA control region. Mar Mamm Sci 17:249-263

Möller LM, Beheregaray LB (2004) Genetic evidence for sexbiased dispersal in resident bottlenose dolphins (Tursiops aduncus). Mol Ecol 13:1607-1612

Möller LM, Beheregaray LB, Harcourt RG, Krützen M (2001) Alliance membership and kinship in wild male bottlenose dolphins (Tursiops aduncus) of southeastern Australia. Proc R Soc Lond B 268:1941-1947

Möller LM, Wiszniewski J, Allen SJ, Beheregaray LB (in press) Habitat type promotes rapid and extremely localized genetic differentiation in dolphins. Mar Freshw Res

Natoli A, Birkun A, Aguilar A, Lopez A, Hoelzel AR (2005) 
Habitat structure and the dispersal of male and female bottlenose dolphins (Tursiops truncatus). Proc R Soc Lond B 272:1217-1226

Nielsen EE, Hansen MM, Ruzzante DE, Meldrup D, Gronkjaer P (2003) Evidence of a hybrid-zone in Atlantic cod (Gadus morhua) in the Baltic and the Danish Belt Sea revealed by individual admixture analysis. Mol Ecol 12: 1497-1508

O'Hara TD, Poore GCB (2000) Patterns of distribution for southern Australian marine echinoderms and decapods. J Biogeogr 27:1321-1335

Palumbi SR (2004) Marine reserves and ocean neighborhoods: the spatial scale of marine populations. Annu Rev Environ Resour 29:31-68

Park SDE (2001) Trypanotolerance in West African cattle and the population genetic effects of selection. $\mathrm{PhD}$ thesis, University of Dublin

Petrusevics PM (1993) SST fronts in inverse estuaries, South Australia-indicators of reduced gulf-shelf exchange. Aust J Mar Freshw Res 44:305-323

Piry S, Alapetite A, Cornuet J-M, Paetkau D, Baudouin L, Estoup A (2004) GeneClass2: a software for genetic assignment and first-generation migrant detection. J Hered 95: 536-539

Posada D, Crandall KA (1998) MODELTEST: testing the model of DNA substitution. Bioinformatics 14:817-818

Pritchard DW (1967) What is an estuary: physical viewpoint. In: Lauff GH (ed) Estuaries. American Association for the Advancement of Science, Washington DC, p 3-5

Pritchard JK, Stephens M, Donnelly P (2000) Inference of population structure using multilocus genotype data. Genetics 155:945-959

Raymond M, Rousset F (1995) Population genetics software for exact tests of ecumenicism. J Hered 86:248-249

Rice DW (1998) Marine mammals of the world: systematics and distribution, Vol 4, special publication. Society for Marine Mammalogy, Lawrence, KS

Rice W (1989) Analysing tables of statistical tests. Evolution 43:223-225

Schneider S, Roessli D, Excoffier L (2000) Arlequin, Ver 2.000:

Editorial responsibility: Rory Wilson (Contributing Editor), Swansea, UK a software for population genetics data analysis. University of Geneva

Shaughnessy P, Kirkwood R, Cawthorn M, Kemper CM, Pemberton D (2003) Pinnipeds, cetaceans and fisheries in Australia: a review of operational interactions. In: Gales N, Hindell M, Kirkwood R (eds) Marine mammals: fisheries, tourism and management issues. CSIRO, Collingwood

Sunnucks P, Wilson ACC, Beheregaray LB, Zenger K, French J, Taylor AC (2000) SSCP is not so difficult: the application and utility of single-stranded conformation polymorphism in evolutionary biology and molecular ecology. Mol Ecol 9: 1699-1710

Tamura K, Nei M (1993) Estimation of the number of nucleotide substitutions in the control region of mitochondrial DNA in humans and chimpanzees. Mol Biol Evol 10: 512-526

Valsecchi E, Amos W (1996) Microsatellite markers for the study of cetacean populations. Mol Ecol 5:151-156

Van Oosterhout C, Hutchinson WF, Wills DPM, Shipley P (2004) MICRO-CHECKER: software for identifying and correcting genotyping errors in microsatellite data. Mol Ecol Notes 4:535-538

Wang JY, Chou LS, White BN (1999) Mitochondrial DNA analysis of sympatric morphotypes of bottlenose dolphins (genus: Tursiops) in Chinese waters. Mol Ecol 8: 1603-1612

Waples RS, Gagiotti O (2006) What is a population? An empirical evaluation of some genetic methods for identifying the number of gene pools and their degree of connectivity. Mol Ecol 15:1419-1439

Ward TM, McLeay LJ, Dimmlich WF, Rogers PJ, McClatchie S, Matthews R, Kampf J, Van Ruth PD (2006) Pelagic ecology of a northern boundary current system: effects of upwelling on the production and distribution of sardine (Sardinops sagax), anchovy (Engraulis australis) and southern bluefin tuna (Thunnus maccoyii) in the Great Australian Bight. Fish Oceanogr 15:191-207

Wilson GA, Rannala B (2003) Bayesian inference of recent migration rates using multilocus genotypes. Genetics 163: $1177-1191$

Submitted: September 28, 2006; Accepted: January 12, 2007 Proofs received from author(s): June 19, 2007 